\title{
Supply Networks and Value Creation in High Innovation and Strong Network Externalities Industry
}

\author{
Fernando Claro Tomaselli', Luiz Carlos Di Serio²
}

\begin{abstract}
The rapid developing product and service markets and developments in information technologies have accelerated growth in outsourcing of peripheral activities and critical business as well, enhancing the importance of network supply chain management. This paper analyzes the dynamics of supply chain management and the creation of value in an industry with strong network effects and constantly introduction of disruptive technologies, the videogame industry. This industry evolves at a high velocity, with a lifecycle of five to six years for consoles, which features a new generation of consoles, where new companies and technologies appear and disappear at each generation.
\end{abstract}

Keywords: videogame; network externalities; supply networks, rbv, relational view, disruptive technology.

\footnotetext{
1,2 Department IMQ , Fundação Getulio Vargas - FGV -EAESP, Rua Itapeva, N 474 - 9 andar, São Paulo, SP, Brazil.

'E-mail: Fernando.tomaselli@fgv.br.
} 


\section{Introduction}

The rapid developing product and service markets and developments in information technologies have accelerated growth in outsourcing of peripheral activities and critical business as well (Mclvor, 2009). Due to that, the supply management and the interaction and development of resources and capabilities between commercial partners as a form to create value and competitive advantage (Brito and Brito, 20II) is more important than ever and the introduction of new technologies and it's impacts on the make-or-buy decisions of the firm is an important (Fine, 2000; Perrons et al., 2004). Recently, the analysis unit is the supply networks instead of supply chains, and they could be considered as interdependent, interconnected and sometimes integrated supply chains (Corrêa, and Xavier, 20I3)

Companies such as Sony and Microsoft (MSFT), now compete for the home video game USD 58 Billion market (Nayak, 2013) market, with the video game console as the center of home entertainment that could dominate the digital living room as it is increasingly occupying the space of traditional media such as television, especially among the new generations. Two factors make the video game industry particularly interesting for study. First, the industry of video game consoles has a high clockspeed (Fine, 2000), with a life cycle of (approximately) five years for consoles, where each cycle introduces an incremental or disruptive technological innovation that can lead to the success and failure of several companies (Christensen, 2000; 2002). Second, there is a unique integration between consoles (hardware) and its main complementary good, the games (software) that form an integrated system that enables the study at each cycle of how the supply networks are managed in order to create value, using the traditional manufactured good approach as well as an information economy good approach in a sector characterized by strong network effects (Katz and Shapiro, 1985).

Our overarching objective is to enhance the understanding of the network supply management role in the value creation analyzing the case of the networks in the home video game. To do so, this paper seeks to identify the critical success factors in the industry of home video game consoles and how Supply networks management influence this. For the development of this research, we consider two specific objectives: mapping the values networks, power relationships; and identifying the vertical and horizontal movements of the main actors at each new cycle in in order to migrate to links that have better earning potential; and the strategy of companies in the network management to prevail in a segment with high clockspeed and strong network effects were players are competing fiercely with each other exploring interconnected supply networks.

\section{Theory development and literature review}

\section{I.The make-or-buy decision and Resources in in- ter-organizational Supply Networks}

To Fine (1998; 2000), "clockspeed," is the velocity of change of the firms business environment due to technological advances. For fast-clockspeed industries, as the home videogame, supply chain design is the core competency since the question to choose what capabilities along the value chain to invest in and develop internally, and which to allocate for suppliers is of the most importance. His double helix model analyzes the capabilities of the company and its chain, based on an infinite loop between vertically integrated industries and industries horizontally disintegrated with forces always pushing on either side of the helix and competitive advantage is only temporary. In many cases, the greatest battles are in vertical competition, between the links in the chain, and not with traditional competitors (Fine, 1998; 2000).

A major shortcoming of the RBV is its focus on a focal firm that masks the complexity involved when considering capabilities, routines, and resources in a broader system of organizations, including interactions with customers and trading partners and the formation of alliances and collaborative projects for learning. The value creation goes beyond the formal boundaries that define the company and depends on the management of partnerships with internal and external actors (Brito and Brito, 20I I; Holweg and Pil, 2008) to address this issues, were developed the Relational View expanding the unit of analyses from the firm to the network and organizational interactions as routine and process as a source of competitive advantage and value (Dyer and Singh, 1998). The relationship of the firms is not only a question of governance but a productive resource for value creation (Madhok and Tallman, 1998). Nevertheless, the resources generated by the inter-organization relations do not have the same impact in all the firm of the network, depending on the singular resources, characteristics and absorption capacity of each participant in the network (Zen et al., 2013).

\subsection{Technological Changes}

Christensen (2000) defines two concepts of technological change: "incremental changes", which are enhancements of the product on the dimensions of performance usually valued by customers, and disruptive innovations, which redefine the trajectories of performance and bring a new proposal of value to the customer and additional features. Disruptive innovation is a novel idea or behavior, that, when introduced in organizational settings, cause dramatic changes in the architecture of work process (Sherif et al., 2006) 
In uncertain markets, with a high clockspeed the competitive advantage is in the disruptive innovation and not on incremental ones, the path to innovate is revolutionary and not evolutionary. Companies failed also in cases that the technology already existed, because when they decided to adopt the technology it was too late or they fail to use it. For Christensen (2000), there are three factors linked to the success of an organization faced with a change: its resources, its processes and its values, which form a group called the RPV structure.

\subsection{Economic Principles}

Technology changes, economic laws do not, as stated by Shapiro and Varian (1998), the economic laws do not change with a new technology, however, some economic principles have stronger effects on markets based on information technology. One principle is network externalities, that is when products or goods have increased its utility as other agents consume them as well, therefore the value of the product to a user is given by the number of users that exist for that product. (Farrell and Saloner, 1986; Gallaugher and Wang, 2002; Kauffman et al., 2000).

These network externalities are common in hardwaresoftware paradigm, characteristic of the home video game market, also called Two-sided Network where the value of the platform for the user is given by the number of users across the network. Players will favor the platform (console) with the highest number of games and with larger number of users, because it can more easily swap games with friends or find partners to play online at the same time game developers create games for platforms with a greater number of users to retrieve their high initial costs (Eisenmann et al., 2006; Katz and Shapiro, 1985).

There is a strong Positive Feedback when each new member of the network increases its value, which in turn brings more members. Therefore, subsidizing the hardware to generate profits with the software (games) is common practice. The lower price increases the installed base to reach critical mass, a point where enough users have adopted the technology so that it becomes self-sustaining adoption, when more users are attracted to it, increasing its value and attracting even more users, entering a positive spiral (Shapiro and Varian, 1998; Sledgianowski and Kulviwat, 2009). Subsidizing the console has another benefit, to put the customer in lock in. Every time the customer (a company or a person) is going to change a technology it has switching costs from one system to another.When the cost of exchange associated with change of a brand or technology to another is substantial, users face a barrier to the free exchange of technology by another, and is in a state of lock in (Shapiro andVarian 1998).

\section{Method}

A multiple case study approach, as proposed by Yin (20I3), was used in this research. The units of analyses were two interrelated networks of the home video game industry. The home video game industry was selected due its fast clockspeed and market relevance. The two networks were selected because of a number of reasons. The strongest links of each network were the two console manufacturers that had most recently entered in this market and despite that already had a leading position. In one network, the strongest link were one of the most important electronic goods manufacturer in the world Sony and the other one were one of the biggest software developer in the world, MSFT. That would allow an analysis of different approaches in the networks exploring different core competences and strategies. The selected Networks are the focal networks for the study and the actor of the networks are the two strongest links and the other participants of the network. We sought to identify the critical factors of success of the network management at the video game industry, and did not focus on any company mistakes or successes, nor did we attempt to criticize their approaches.

We initially performed a detailed analysis of secondary data available in historical archives, statistics and previously conducted studies and five open and informal conversations with game developers participating in the SBGames, The Brazilian Symposium for game developers, which allowed the selection of individuals for interviews and the preparation of the roadmaps of the interviews, in addition to enabling the identification of the key links in the value chain and its general dynamic.

The interviews were semi-structured, open and recorded, with specialists in the video game market, selected for relevance, knowledge of the subject and convenience: (I) the chairman of ABRAGAMES (Brazilian Association of Electronics Games Developers) and manager of a console company, (2) the Director of Products and New Business for a game developing company and Executive Manager of an incubator for developers of games and digital entertainment and CEO of a game portal of a telecom group, (3) a Ph.D. in artificial intelligence from the University of Paris, a researcher in the area games at a Brazilian university and partner at a a mobile games firm, (4) One of the owners of the leading game developers in Brazil), former chairman of ABRAGAMES, (5) the General Manager of the division "mobile" of the biggest Brazilian console producer, focused on developing and distributing games and related content for mobile phones, market veteran for Brazilian games, and with experience as a journalist, consultant and executive in the market for video games. 
The data of the interviews were analyzed via content analyses and to assure construct validity, multiple sources of evidence were used to triangulate data. Internal validity was ensured by using within-case analyses and cross case analyses. To ensure external validity, the study used replication logic to analyze and conduct each case and for reliability there was the preparation of the semi-structured interview questionnaire, that was pre-tested and all procedures were applied consistently in every occasion.

\section{Results}

\section{I.The entry of Sony in the market for home con- soles}

Sony's first console, the PlayStation, had a key point, the use of the CD-ROM in place of ROM cartridges. Sony exploited its media capabilities to the extreme, changing the form of distribution of games in Japan. In the past, publishers often bought large quantities of a title and distributed them to retailers. The minority of games was successful, so the wholesaler tried to unload much of the stock quickly, but if the game was a success, wholesalers would wait for the price rise before selling. This occurred because the cartridge ROM (a semiconductor memory packaged in a cartridge), was expensive to manufacture and slow to produce. Time is a critical factor in this business -- a game can go "out of fashion" in a few months. The high cost was reflected in the final price for the consumer of USD 98 (Asakura, 2000).

The competitors maintained this structure for the CDs but Sony used the $C D$ as a disruptive technology, using the structure of Sony Music for manufacturing CDs cheaper and faster and adapted the business model of the music industry, making a small initial print, increasing production if the title sold well. Thus, Sony avoided the insurance and maintained the wholesaler and publisher margin with a USD 58 price to the end user.The publisher (mainly the smaller ones) would also benefit from the smaller investment for each game.

Another key factor for success was the ability of Sony to reduce hardware costs. The hardware lasts for the life of the console so the potential to reduce costs is essential for success. It is estimated that Sony lowered the costs of the console from USD 450 to USD 80 in five years (Takahashi, 2002). The reduction of costs was not aimed at increasing profits, but at reducing prices to increase the installed base, increasing installed base and positive feedback, and allowing Sony to bring more developers to the console, with whom they sought to create a strong relationship (Deshpande, 2002).

\subsection{Playstation 2 (PS2) and Sony hegemony consoli- dation}

With the PS2, Sony launched the approach of a "Trojan Horse" to dominate the new digital living room, announcing it as a home entertainment center, and digital entertainment gateway for the home, playing games, CDs, DVDs and MP3s, with backward compatibility with original Playstation Games. As the game console was subsidized, it became the cheapest DVD player available in the Japanese Market and the Japanese DVD market doubled in one month due to its launch (Deshpande 2002). It was a success, with impressive initial sales figures. Sony's head start made it difficult for MSFT and Nintendo to catch up. With it's big installed base, Sony was able to afford huge advanced payments for the publishers in exchange for exclusive rights to the games because their sales were likely to be very profitable, especially because they were associated with Sony's name. (Takahashi, 2006).

Sony made an aggressive price reduction on this console, merged its CPU and graphic chip into one single chip, and released a much smaller version of the console, the "slim" in 2004. They further reduced the price from USD 299 at launch to USD I49 in 2004 (Takahashl, 2002; 2006), with an actual price of USD 129.

\subsection{The current generation:The PlayStation 3 (PS3)}

The PS3 represented an intensification of the Trojan Horse approach initiated with PS2. Sony joined Toshiba (its competitor for the Blu-ray format with the HD-DVD) and IBM to develop the Cell Chip, the heart of PS3 (Lee et al., 2006). With this console, Sony was trying to popularize the Blu-ray technology as a substitute for the DVD and to introduce its cell chip that the company plans to use in several electronics devices. However, this technology were complex and expensive and Sony had to heavily subsidize the PS3 in the beginning (Lee et al., 2006), in order to gain market share and consolidate Blu-ray as the substitute of the DVD. Additionally, this technology implies a big change in the way games are developed, generating an increase in the time necessary for the developers to fully explore the hardware potential and increasing the cost of development (Ofek, 2005). The lack of good games and high cost of the console have affected the console initial sales. Sony has lost its place as the sole market leader.

\subsection{MSFT's entrance in the home video game con- sole market}

MSFT already had a tradition of developing PC games and wanted to defeat Sony's vertical structure with a more horizontal one, with its software on a console with PC-based hardware, obtaining large scale economics and the benefits 
of creating a PC game for stable hardware. Nevertheless, MSFT had to learn how to manage a complex hardware supply chain and the development of an advanced hardware system. Due to the business model with subsidized hardware, none of the big PC manufacturers were interested in manufacturing the console, so MSFT hired Flextronic, an electronics manufacturing services (EMS) company that provides electronics manufacturing facilities and services. Parts such as the microprocessor and graphics chip were bought from the vendor directly by MSFT with Intel and Nvidia (with a gradual price reducing schedule) and were delivered to Flextronics (Lee et al., 2006)

MSFT had problems with its supply chain, Nvidia delayed the final version of the chips and there were problems with Intel's motherboard and Flextronics IT system, because its data base was not big enough to track all the components. (Takahashi, 2002). MSFT focused on obtaining the support of developers and publishers for the console in terms believed to be more favorable than those of the competition and development tools similar to the PC, easier to use and well known by the programmers (Greco and Appleyard, 200I). MSFT's first-party development team increased its expertise by buying other game developers and seeking agreements for exclusive games for the Xbox. By the time of the launch, Sony had $55.57 \%$ of the market, Nintendo $33.8 \%$ and Sega $10.6 \%$. MSFT launched the Xbox at the same price of the PS2, USD 299, which was less than its production costs (Takahashi, 2002).

Similar to the PS2, the Xbox was able to play DVDs, CDs and MP3. But there were a few differences such as the hard drive that could store content, which could improve the online experience. The Xbox Live, the online multiplayer gaming and digital contents delivery service from MSFT, was launched at the end of 2002 allowing the exploration of new business models with alternatives to distribute contents (such as music and videos), games and services.

In May 2002, Sony reduced its price to USD 199 and MSFT matched, even though the loss per unit sold was going to be higher; reducing the cost of the console was difficult because it used PC standard parts that were already cost reduced, and suppliers of major components such as Nvidia and Intel were not willing to reduce the price to the level MSFT needed, and MSFT was in lock in with them. By the end of 2005, MSFT had sold 22 million Xbox units, Nintendo 20 Million Game Cubes and Sony more than 90 Million PS2 units. The market estimated that MSFT had lost almost USD 4 Billion by June 2005 (Guth, 2005).

\subsection{The new MSFT attack, the XBox 360}

The main objective was to retire the Xbox sooner in order to limit losses and launch the new generation before Sony, MSFT did not want to be locked in again by its suppliers, however, it wanted to continue to use the manufacturing capabilities of third parties; therefore, it selected IBM as a partner for the CPU, and ATI for the graphic chip (GPU).ATI was going to receive a fee for designing the chip and MSFT would own the design allowing MSFT to select any chip producer it needed. IBM agreed to license its technology for the Chartered Semiconductor Co, a second alternative for MSFT to build the chip. Nevertheless, to allow backward compatibility, it had to pay royalties to Nvidia for the new consoles sold. To manage GPU chip manufacturing, MSFT implemented an enterprise resource planning (ERP) solution to better manage its supply chain and developed an internal Business Integration and Intelligence solution, to create standardized data exchange between its ERP and contract manufacturers and subcontractor suppliers systems. The strategy of simplifying game development and seeking developer's support (as well as buying them) continued. The use of third parties had gone beyond the hardware; MSFT hired developers from China and India to develop part of the games (similar to car design, for example) and developed tools to coordinate the efforts. MSFT's major bet was the Xbox live. It improved the services and download possibilities for games and contents, and tried to create a feeling of community to attract a higher number of users, using also casual games (simpler and faster games, generally without a storyline, like a puzzle for example) with low development cost and downloadable directly by the users. This resulted in millions of units sold at a small price via internet and diminished the risk of development and piracy being a critical additional revenue generator for the razors and razor blade model.

\subsection{MSFT and Sony case study analysis}

Strong network effects characterize this market, and both companies tried to maximize it by gaining the support of publishers and developers from the start. Nevertheless, Sony was more successful in gaining this support the first time the two companies competed directly against each other. The main factors for this success were: the success of its first console that leveraged the PS2; the power of the hardware; Sony's control of the value chain allowing it to reduce costs and gain market share. However, MSFT had an impressive increase in its ability to manage the value chain with the current generation of its console and was able to invert the situation.

Sony and MSFT tried to verticalize part of the value chain, buying and creating internal publishing and development teams, but, despite this effort, the power in the value chain

ISSN: 07 I8-2724. (http://www.jotmi.org)

Journal of Technology Management \& Innovation @ Universidad Alberto Hurtado, Facultad de Economía y Negocios. 


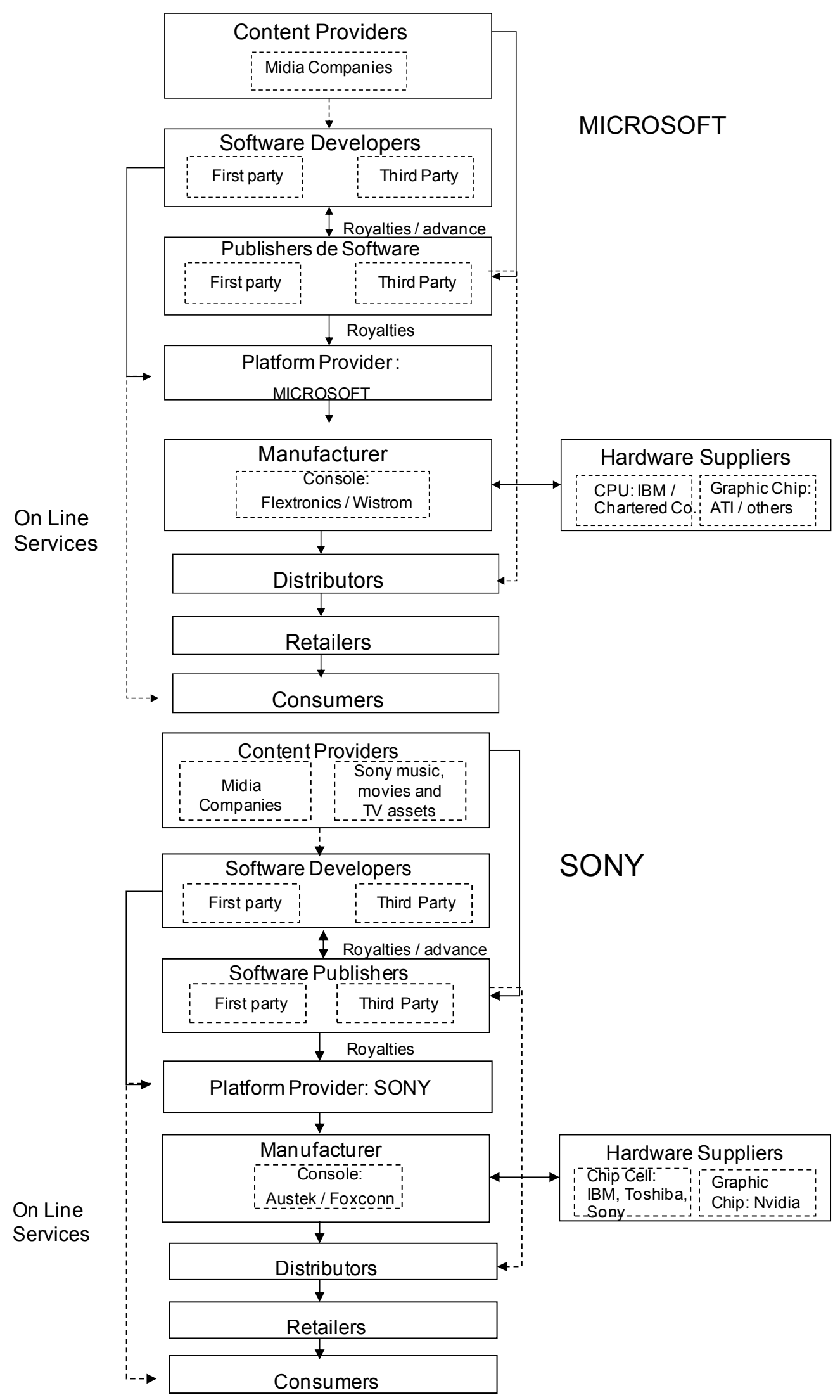

Figure I: Sony PS3 and Xbox 360 Network. Source: Elaborated by the authors 
was moving towards the publishers. Sony had a strong bargain power and sales potential due to its big installed base, allowing Sony to obtain several exclusive games. But with the small PS3 penetration (mainly due to the high cost of the console) and its programming difficulty, this advantage quickly eroded. Sony's value chain is more vertical, since the company can generate intellectual property from its music, film and television companies, and make them exclusive for the console, and Sony uses its experience as a hardware manufacturer to manufacture key parts of the console, such as the chip cell, the console heart, developed in a joint venture with IBM and Toshiba (Sony's competitor against the Blu-ray with its HD DVD format).

In this generation, the approaches of the two companies converge, as Sony used EMS to manufacturer the console (like MSFT), using Austek and Foxconn for the task, and MSFT used ATI to develop the graphic chip, but retained the intellectual property rights. Additionally, MSFT could manufacture it with any supplier but negotiated with IBM, the developer and manufacturer of the CPU and used a second manufacturer, the Chartered Semiconductor Co, in order to reduce its dependency on the suppliers. It is interesting to note that Sony's approach became more similar to MSFT's approach when it horizontalized parts of the hardware manufacturing in the value chain, and MSFT becomes similar to Sony when its verticalized the intellectual property of key parts of its hardware.

Sony uses its core competences as a hardware manufacturer and explores the power of its hardware, and MSFT uses its experience as a software company to offer a new integrated experience for the users with a new business model. The greatest risk of Sony's strategy is the high cost of its hardware and the fact that it may be offering more technology then the clients need or are willing to pay for. MSFT is betting on the integration of software, hardware and services with the single and integrated experience concept, however, its main competitive advantage, the Xbox Live, is easier to copy. (Sony is advancing in this way), rather than improving the hardware that is "locked" until the next generation of the console.

\section{Discussion}

This Study aim was to understand how the Supply Chain Management could generate value (and therefore market leadership) in the industry of home videogame consoles. In order to accomplish that, an analysis of the agents in this Network, the relation between the links, as well as the vertical and horizontal movements to links in the network with better revenue potential was done, as well as an analyzes of the strategies of the main actors of the network at each introduction of a new technology, ( disruptive or incremental) at the beginning of a console generation. This analysis were made with the resource-based-view and relational view, economic principles as network externalities and lock in as well as theory regarding disruptive and incremental innovations. As per this analyses, critical success factors in the home console video game is building the biggest possible installed base and game options exploring the strong network effects of the industry, nevertheless, to do so a leadership in hardware cost is mandatory and it cannot be obtained without an appropriate network management which include rethinking you process and sometimes even your business model due to new disruptive technological innovations while avoiding to be locked in.

This industry is dominated by the companies that retain the console technology, who sought to increase the partnership and joint ventures for the development of the consoles, adopting a strategy that is more horizontal and modular, focusing on the tasks with more added value. Although Sony's approach is more vertical than MSFT's, both seek to control the value chain with strategic partnership and at the same time, avoid being locked into a given technology. In addition, there is the continuous increase in the publisher's influence, as suppliers of essential complementary goods to the consoles - the games - that are gaining power in relation to Sony and MSFT, as they verticalized power that used to be from the developers and the platform providers.

This research contributes to the debate of the make-or-buy decision, with a Network approach exploring a industry with characteristics of the traditional economy, by the hardware side, and the information or digital economy, by the software side, using supply chain, economics and innovation theory and has a contribution for practicioners since more companies are seeking an integration between software and hardware (as Apple and Google) with networks that are becoming more similar to the ones analyzed in this study although the power of generalization of this study is limited. Future research could address the following issues: (I) An economic analysis of the markets that are emerging in virtual worlds such as MMOs like Second Life and World of Warcraft; (2) Alternative ways to distribute and sell content over the Internet and its impact on the industry business model. 


\section{References}

ASAKURA, R (2000). Revolutionaries at Sony: The making of the Sony PlayStation and the visionaries who conquered the world of video games. McGraw-Hill, New York.

BRITO, R.P, Brito, L.L. (20II). Vantagem Competitiva: uma proposta de definição constitutiva e sua relação com desempenho. Paper presented at the proceedings of the XXV encontro ANPAD. Rio de Janeiro -RJ

CHRISTENSEN, C. M. (2000). The Innovator's Dilemma. HarperCollins, New York.

CHRISTENSEN, C. M. (2002). The rules of innovation. Technology review, I05, 33-38

CORRÊA, H.L., Xavier, L.H., (20I3). Concepts, design and implementation of Reverse Logistics Systems for sustainable supply chains in Brazil. Journal of Operations and Supply Chain Management, 6(I), I-25. DOI: 10.12660/joscmv6nIpI-25

DESHPANDE, R. (2002). Sony Playstation 2. Harvard Business Publishing Case 9-502-016, Harvard Cambridge.

DYER, J.H., Singh, H. (1998). The relational view: Cooperative strategy and sources of interorganizational competitive advantage. Academy of management review, 23(4), 660-679. DOI: $10.2307 / 259056$

EISENMANN, T., Parker, G., and Van Alstyne, M. W. (2006). Strategies for two-sided markets. Harvard Business Review, 84(10), 92-101.

FARRELL, J.; Saloner, G. 1986. Installed base and compatibility - innovation, product preannouncements, and predation. American Economic Review, 76(5), 940-955.

FINE, C.H., (1998) Clockspeed: Winning industry control in the age of temporary advantage. Perseus Books, Massachusetts.

FINE, C. H. (2000) Clockspeed based strategies for Supply Chain Design, Production and Operations Management, 9(3), 2|3-22I .

GALLAUGHER, J. M., WANG, Y. M. (2002). Understanding network effects in software markets: Evidence from Web server pricing. MIS Quarterly, 26(4), 303-327. DOI: |0.2307/4|323| I

GRECO, J., Appleyard, M. (200I) Microsoft's XBox gamble. Tuck School of Business case study 06-00I I. Dartmouth.
GUTH, R.A.(2005) Getting Xbox 360 to Market. The Wall Street Journal. http://online.wsj.com/news/articles/ SBI I32273 I6 I I 7900733 [Accessed December 04, 20I3]

HOLWEG, M., Pil, F.K. (2008). Theoretical perspectives on the coordination of supply chains. Journal of operations management, 26, 389-406. DOI: I0.10I6/j.jom.2007.08.003

KAUFFMAN, R. J., McAndrews, J., Wang, Y. M. (2000). Opening the "black box" of network externalities in network adoption. Information Systems Research, I I ( ), 6I-82. DOI: 10.1287/isre.II.I.6I.I I783

KATZ, M. L., Shapiro, C. (1985). Network externalities, competition, and compatibility. American Economic Review, 75(3), 424-440.

LEE, H; Hoyt, D; Holloway, C. (2006). Evolution of the Xbox Supply Chain. Stanford Graduate School of Business case GS-49. Stanford University, Stanford.

MADHOK, A; Tallman, S.,B.(1998) Resources, transactions and Rents: Managing value through interfirm collaborative relationships. Organization Science, 9(3), 326-339. DOI: 10.1287/orsc.9.3.326

McIVOR, R. (2009). How the transaction cost and resourcebased theories of the firm inform outsourcing evaluation. Journal of Operations management, 27(I), 45-63. DOI: 10.1016/j.jom.2008.03.004

NAYAK, M.F. (2013). A look at the $\$ 66$ billion video-games industry. http://in.reuters.com/article/2013/06/l0/gameshow-e-idINDEE9590DW20130610 [Acessed September 7,2013]

OFEK, E. (2005). Home Video games: Generation Seven. Harvard Business Publishing case 9-505-072, Harvard Cambridge.

PERRONS, R.K., Richards, M.G., Platts, K. (2004). The effect of industry clockspeed on make-or-buy decisions in the face of radical innovations: an empirical test. International Journal of Innovation Management, 8(4), 43 I-454.

SHAPIRO, C., Varian, H. R (1998). Information Rules: A Strategic Guide to the Network Economy. Harvard Business School Press. Boston.

SHERIF,K., Zmud, R.W., Browne, G. J.(2006). Managing peerto-peer conflicts in disruptive information technology innovations: the case of software reuse. MIS quarterly, 30(2), 339-356. 
SLEDGIANOWSKI, D., Kulviwat, S. (2009). Using social network sites:The effects of playfulness critical mass and trust in a hedonic context. Journal of Computer Information Systems, 49(4), 74-83.

TAKAHASHI, D. (2002). Opening the Xbox. Prima publishing, Roseville.

TAKAHASHI, D. (2006). The Xbox 360 Uncloaked. Lulu Press.

YIN, R. (20I3) Case Study Research: Design and Method. 5th edition, Sage. Thousand Oaks.

ZEN,A. C.; Dalmoro, M.; Fensterseifer, J.E.;Wegner, D. (20I3). $O$ desenvolvimento de recursos em redes interorganizacionais e o processo de internacionalização: $O$ Caso Wines of Brasil. Revista Ibero-Americana de estratégia -RIAE, , I2(I), I07-I30. 